\title{
Does the Dogs of the Dow Theory Work at the Sectoral Level?
}

\author{
Doh-Khul Kim ${ }^{1}$, Michelle Nguyen ${ }^{1} \&$ Kyle Arbet ${ }^{1}$ \\ ${ }^{1}$ Department of Accounting and Finance, North Central College, Naperville, IL, USA \\ Correspondence: Doh-Khul Kim, Associate Professor, Department of Accounting and Finance, 30 N. Brainard \\ St., North Central College, Naperville, IL 60540, USA. Tel: 630-637-5243. E-mail: dkim@ noctrl.edu
}

Received: July 9, 2020

doi:10.5539/ijef.v12n9p46
Accepted: July 23, 2020

Online Published: August 5, 2020

URL: https://doi.org/10.5539/ijef.v12n9p46

\begin{abstract}
One of popular theories in technical analysis is the Dogs of the Dow (DoD) theory. According to this strategy, the average market can be outperformed using 30 firms of Dow Jones Industrial Average (DJIA) index. Since DoD was introduced, there have been numerous studies on the validity of the theory. However, only contradicting results have been found, so the research has produced no robust consensus on the theory. In addition, most of the research was performed using aggregate stock market data. The purpose of our research is to determine whether the DoD theory is valid at the sectoral level. We find that returns of top 5 highest dividend-yield firms are higher than average return of each sector. However, the additional returns of those 5 firms are not meaningful enough if we take into account tax on profits and trading costs, which does not validate the DoD theory at the sectoral level.
\end{abstract}

Keywords: Dogs of Dow theory, sectoral level, dividend yield

JEL Codes: G10 (General Financial Markets), G14 (Information and Market Efficiency)

\section{Introduction}

The Dogs of the Dow (DoD) theory is a simple strategy introduced by J. Slatter in The Wall Street Journal in 1988. Since then, it has gained popularity in financial markets thanks to in-depth analysis and research by O'Higgins and Downes (1992), among many others.

The DoD theory states that an investor can outperform the average market using 30 firms from the Dow Jones Industrial Average (DJIA) index. It proposes that individuals invest in 10 firms that have the highest dividend yields (dividend/stock price) among 30 firms on the last (or first) trading day of the year. Then, the investors hold the stocks for an entire year and sell them on the last trading day of the year. If one repeats this strategy (buy on the first day, hold for an entire year, and sell on the last day) every year, he or she is more likely to outperform the average market (using both risk-adjusted and non-adjusted returns) in the long term.

Higher dividend yield is made when a firm is undervalued (comparing to fundamental value) and/or when a firm pays higher dividends (which is an implication of strong financial status). Hence, the DoD theory is very logical theoretically. However, there is no robust consensus on the validity of the theory in the market. Some have found the theory to be well confirmed (Chong \& Luk, 2010; Tissayakorn et al., 2013; Soomro \& Haroon, 2015; Yan et al., 2015), whereas other studies contradict the theory (Domian et al., 1998; Hirschey, 2000; Da Silva, 2001; Kim, 2019).

Yan et al. (2015) supported the validity of DoD theory by demonstrating higher returns upon following this strategy than the average market return in Taiwan. Using data in Pakistan, Soomro Haroon (2015) also showed that the DoD theory works well with some limitations applied. Earlier similar results were found in a study by Tissayakorn et al. (2013), who showed the outperformance by the DoD theory in the Thai stock market. Chong and Luk (2010) also confirmed the theory using blue-chip stocks of the Hang Seng Index in Hong Kong.

McQueen et al. (1997) showed that higher returns are possible using the DoD strategy. However, they showed that this outcome is only possible when trading costs and taxes are excluded. Later, Domian et al. (1998) explained that the outperformance in the framework of overreaction hypothesis can exist in the equity market. In his in-depth research, Hirschey (2000) showed that the DoD theory is not confirmed in the U.S. market. His research has used adjusted returns after reflecting all the taxes and rebalancing costs. Even though he demonstrated some years of outperformance by following the DoD strategy, overall returns were no better than 
the average market. His research supported the Efficient Market Hypothesis. In a study among several Latin Americans countries, Da Silva (2001) also showed that the DoD theory was not valid. Some years of outperformance with the strategy turned out to be non-statistically significant. Using data from 2000 to 2017 , Kim (2019) also showed that the theory does not work well in the U.S. equity market if both tax and trading costs are included.

All of the extant research has been performed using broad stock market data in numerous countries, whereas little research has been performed at the sectoral level, even though it is worth extending the theory to specific sectors. Each sector has its own characteristics that can differ from the broad market. Since 2000, a great number of exchange-traded funds (ETFs) representing sectors and industries have been introduced and traded as a way of engaging in passive investment. The ETFs (closed-end investment) have been growing at a faster pace than the traditional mutual funds (open-end investment) due to several advantages that the ETFs provide, such as easy access and lower management costs. According to Morningstar (2018), there has been more than $\$ 1$ trillion in cash inflows into ETF between 2006 and 2018, whereas \$1.5 trillion has left the actively managed mutual fund industry.

Extending the DoD theory to the sectoral level is meaningful by itself, as it can provide an opportunity for investors to outperform the average market. In their sectoral-level analysis using both OLS and panel regression models, Kim and Najrin (2020) found results confirming the stock valuation model by showing that dividend positively affects the equity market. The main purpose of this study is to investigate the validity of the DoD theory at the sectoral level, which is also the aspect in which this study differs from other previously performed research. Using 11 sectors of the U.S. equity market along with the most representative exchange traded funds (ETFs), we find that equally weighted investments of the top 5 highest dividend-yield firms (out of the top 10 holding firms that pay stable dividends during the data period examined) do not meaningfully outperform the ETF and the average of the top 10 holding firms at the sectoral level, except for one sector if the tax and trading costs are controlled. This finding suggests that no meaningful higher returns are possible, even if we narrow our investments into 5 firms based on their dividend yields at the sectoral level. Any annual dividend-based portfolio rebalancing does not outperform the passive long-term investments through ETF or the top 10 holding firms due to taxed on profits and trading costs. This paper presents the research data in Section 2, offers discussions in Section 3, and provides concluding remarks in Section 4.

\section{Data}

For the sectoral-level analysis, we used the most representative sectoral ETFs from the U.S., whose data ranges between 2010 and 2018 (post-financial crisis period), as shown in Table 1. This research works on 11 sectors from the S\&P 500, and all data of ETFs and firms are from Bloomberg Terminal. During this period of analysis, all ETFs paid dividends four times (in March, June, July, and December) each year. We chose the top 10 holding firms in each ETF that paid uninterrupted dividends during this period in order to improve the accuracy of our research. The top 10 firms of each ETF are shown in Table 2. However, the top 10 firms are updated for each year during the period.

Table 1. 11 Sectors and corresponding exchange-traded funds (following S\&P sector categories)

\begin{tabular}{cc}
\hline Sectors & ETF \\
Consumer Discretionary & XLY \\
Consumer Staples & XLP \\
Energy & XLE \\
Finance & XLF \\
Health Care & XLV \\
Industrial & XLI \\
Materials & XLB \\
Technology & XLK \\
Utilities & XLU \\
(U.S.) Real Estate & IYR \\
Telecommunication & IYZ \\
\hline
\end{tabular}

Note. Each ETF in this paper is the most liquid and biggest in terms of net asset value among each sectoral ETFs. They are issued by State Street SPDR and iShares. 
Table 2. Ten firms in each ETF (as of August 2018)

\begin{tabular}{|c|c|}
\hline & 10 Largest Firms Held by the Fund \\
\hline XLY & $\begin{array}{l}\text { VF Corp (VFC), Home Depot (HD), McDonald's (MCD), Nike (NKE), Yum! Brands (YUM), Lowe's (LOW), Marriot (MAR), } \\
\text { TJX Cos. (TJX), Target (TGT), Best Buy (BBY) }\end{array}$ \\
\hline XLP & $\begin{array}{l}\text { Procter \& Gamble (PG), Coca-Cola (KO), Pepsi (PEP), Wal-Mart (WMT), ALTRIA (MO), Phillip Morris (PM), Costco } \\
\text { Wholesale (COST), Colgate-Palmolive (CL), Mondelez International (MDLZ), Walgreens (WBA) }\end{array}$ \\
\hline XLE & $\begin{array}{l}\text { Exxon (XOM), Chevron (CVX), Schlumberger (SLB), Conoco Phillips (COP), EOG Resources (EOG), Valero Energy (VLO), } \\
\text { Occidental Petroleum (OXY), Oneok Inc (OKE), Williams Co (WMB), Pioneer Natural (PXD) }\end{array}$ \\
\hline XLF & $\begin{array}{l}\text { JPMorgan (JPM), Bank of America (BAC), Wells Fargo (WFC), American Express (AXP), CME Group (CME), US Bancorp } \\
\text { (USB), Chubb Ltd (CB), Goldman Sachs (GS), S\&P Global (SPGI), PNCE Financial (PNC) }\end{array}$ \\
\hline XLV & $\begin{array}{l}\text { Johnson \& Johnson (JNJ), Pfizer (PFE), United Health (UNH), Merck (MRK), Abbott (ABT), Medtronic PLC (MDT), } \\
\text { Bristol-Myers (BMY), Eli Lilly (LLY), CVS Health (CVS), Danaher (DHR) }\end{array}$ \\
\hline XLI & $\begin{array}{l}\text { Boeing (BA), 3M (MMM), Honeywell (HON), Union Pacific (UNP), United Technologies (UTX), United Parcel Service (UPS), } \\
\text { Lockheed Martin (LMT), Caterpillar (CAT), General Electric (GE), Raytheon (RTN) }\end{array}$ \\
\hline XLB & $\begin{array}{l}\text { Linde PLC (LIN), DuPont de Nemours (DD), Ecolab (ECL), Air Products \& Chemicals (APD), Sherwin-Williams (SHW), PPG } \\
\text { Industries (PPG), International Paper (IP), Newmont Mining (NEM), Ball Corp (BLL), Vulcan Materials (VMC) }\end{array}$ \\
\hline XLK & $\begin{array}{l}\text { Microsoft (MSFT), Visa (V), Intel (INTC), Mastercard (MA), Accenture (CAN), Oracle (ORCL), IBM (IBM), Texas Instruments } \\
(\mathrm{TXN}) \text {, Qualcomm (QCOM), Fidelity (FIS) }\end{array}$ \\
\hline XLU & $\begin{array}{l}\text { NextEra (NEE), Duke Energy (DUK), Southern (SO), Exelon (EXC), American Electric Power (AEP), Sempra Energy (SRE), } \\
\text { Consolidated Edison (ED), Dominion Energy (D), Xcel Energy (XEL), Public Service Enterprise (PEG) }\end{array}$ \\
\hline IYR & $\begin{array}{l}\text { Prologis (PLD), Simon Property (SPG), Welltower (WELL), Public Storage (PSA), AvalonBay (AVB), Equity Residential (EQR), } \\
\text { Digital Realty Trust (DLR), Realty Income (O), Weyerhaeuser (WY), Ventas (VTR) }\end{array}$ \\
\hline IYZ & $\begin{array}{l}\text { Verizon (VZ), AT\&T (T), Garmin (GRMN), CenturyLink (CTL), Telephone and Data System (TDS), Shenandoah } \\
\text { Telecommunications (SHEN), Plantronics (PLT), ATN International (ATNI), ADTRAN (ADTN), Consolidated Communications } \\
\text { (CNSL) }\end{array}$ \\
\hline
\end{tabular}

Note. The table shows the top ten holding firms (with stock symbols) that pay stable dividends in each ETF during the period. They are listed in the order of percent out of total assets.

Table 3. Statistic summary of ETFs

\begin{tabular}{|c|c|c|c|c|}
\hline ETFs & $\begin{array}{l}\text { Market Capitalization (as } \\
\text { of Dec. 2019, billion \$) }\end{array}$ & $\begin{array}{l}\text { Number of Holding Firms (Shares } \\
\text { Outstanding in millions) (as of Dec. 2019) }\end{array}$ & $\begin{array}{l}\text { Dividend (\$) and Its Yield } \\
(\%) \text { (as of Dec. 31, 2018) }\end{array}$ & $\begin{array}{l}\text { Average Dividend Yield (\%) } \\
\text { between 2010-18 }\end{array}$ \\
\hline XLY & 15.04 & $65(122.8)$ & $1.33 \& 1.34$ & 1.40 \\
\hline XLP & 13.15 & $34(209.3)$ & $1.54 \& 3.04$ & 2.46 \\
\hline XLE & 11.39 & $29(182.5)$ & $2.03 \& 3.54$ & 2.35 \\
\hline XLF & 25.41 & $67(847.2)$ & $0.50 \& 2.09$ & 1.92 \\
\hline XLV & 20.02 & $62(199.6)$ & $1.36 \& 1.64$ & 1.64 \\
\hline XLI & 11.75 & $71(153.4)$ & $1.39 \& 1.97$ & 1.97 \\
\hline XLB & 3.51 & $29(68.6)$ & $1.11 \& 2.20$ & 2.18 \\
\hline XLK & 26.53 & $71(287.5)$ & $0.99 \& 1.60$ & 1.61 \\
\hline XLU & 10.73 & $29(166.6)$ & $1.76 \& 3.33$ & 3.64 \\
\hline IYR & 4.64 & $117(44.0)$ & $2.65 \& 3.53$ & 3.79 \\
\hline IYZ & 0.384 & $44(12.3)$ & $0.57 \& 2.15$ & 2.61 \\
\hline ETFs & $\begin{array}{c}\text { Annual Dividend Growth } \\
\text { Rate }(\%) \text { between } 2010-18 \\
\end{array}$ & $\begin{array}{l}\text { Annual RoR (\%) between 2010-18 } \\
\text { (dividend included) }\end{array}$ & $\begin{array}{l}\text { Beta Coefficient (between } \\
2017 \text { and 18) } \\
\end{array}$ & $\begin{array}{c}\text { Correlation Coefficient with S\&P } \\
500 \text { (between } 2017 \text { and 18) } \\
\end{array}$ \\
\hline XLY & 13.24 & 15.89 & 1.004 & 0.907 \\
\hline XLP & 25.22 & 10.15 & 1.004 & 0.712 \\
\hline XLE & 9.30 & 2.41 & 0.993 & 0.690 \\
\hline XLF & 15.54 & 10.30 & 1.001 & 0.838 \\
\hline XLV & 11.32 & 13.89 & 1.007 & 0.908 \\
\hline XLI & 11.35 & 11.96 & 1.003 & 0.905 \\
\hline XLB & -0.71 & 7.14 & 1 & 0.848 \\
\hline XLK & 15.07 & 14.67 & 0.999 & 0.908 \\
\hline XLU & 4.16 & 9.98 & 0.990 & 0.326 \\
\hline IYR & 3.74 & 9.59 & 1.016 & 0.586 \\
\hline IYZ & -2.66 & 5.79 & 0.997 & 0.717 \\
\hline
\end{tabular}

Note. The numbers of Beta Coefficient are obtained using the standard deviation of each ETF, SPY and the correlation coefficient between the two, which is standard process for the number. SPY is an ETF that is tracking the S\&P 500. Beta coefficient and correlation coefficient numbers are provided for reference purpose, and all other numbers of different years for each are similar to each other. 
Table 3 shows the statistical summary of all ETFs. As the table shows, XLK, XLV, XLY, and XLI demonstrate a correlation coefficient with the S\&P 500 (between 2017 and 18) of 0.908, 0.909, 0.907, and 0.905, respectively. This implies that the broad market was more led by sectors such as technology, health care, consumer discretionary, and industrial sectors between 2017 and 2018.

Following the DoD theory, we obtained the dividend yield $\left(\mathrm{DY}_{\mathrm{t}}\right)$ of each firm on the last trading day of the prior year using both total annual dividend payments $\left(\mathrm{D}_{t}\right)$ and closing stock price $\left(\mathrm{P}_{t}\right)$, as shown in Equation 1. Then, we chose the top five highest dividend-yield firms for equally weighted investments and compared the average annual Rate of Return (RoR) of these five firms to that of the ETFs and top ten firms. The annual RoR is derived using the first-day and last-day closing stock prices of each firm and ETF. The closing stock price included the year's total dividend payments, as the total RoR is composed of dividend yield and capital gains yield.

$$
D Y_{t}=D_{t} / P_{t}
$$

\section{Discussions}

Table 4. Correlation coefficients between dividend and rate of return (RoR) in aggregate market during 2010-2018

\begin{tabular}{lc}
\hline Annual Dividend Growth Rate and Annual RoR & 0.46 \\
Average Dividend Yield and Annual RoR & -0.44 \\
Average Dividend Yield and Annual Dividend Growth Rate & -0.43 \\
\hline
\end{tabular}

As a first step, we performed correlation coefficient tests between dividend and annual rate of return (RoR) for an aggregate market composed of 11 sectors. As Table 4 shows, the overall relationship between annual dividend growth rate and annual RoR for a market composed of 11 sectors is positive. This implies that the stock valuation model (which predicts a positive relationship between dividend and stock price) works well for the entire market of 11 sectors. In other words, the dividend growth rate has a positive impact on the annual RoR at the aggregate level (or average market), which is in line with the stock valuation model.

However, the average dividend yield has a negative relationship with the annual RoR in the aggregate market of 11 sectors. This finding is at odds with the DoD theory at the aggregate market level, even though the market (under investigation here) is composed of only 11 sectors, and no annual re-balancing is explicitly assumed. Furthermore, the average dividend yield has a negative relationship with the annual dividend growth rate, which implies that a higher dividend yield may result in lower dividend growth going forward. Hence, high dividend yield will lead to lower annual RoR through a lower dividend growth rate in an aggregate market of 11 sectors.

Table 5. Correlation coefficients between dividend and rate of return (RoR) at sectoral level between 2010 and 2018

\begin{tabular}{lcc}
\hline ETFs & Annual Dividend Growth Rate and Annual RoR & Average Dividend Yield and Annual RoR \\
\hline XLY & -0.51 & -0.53 \\
XLP & 0.14 & -0.28 \\
XLE & -0.15 & -0.75 \\
XLF & 0.46 & -0.44 \\
XLV & -0.29 & -0.26 \\
XLI & -0.26 & -0.75 \\
XLB & 0.44 & -0.05 \\
XLK & -0.04 & -0.22 \\
XLU & -0.05 & -0.47 \\
IYR & 0.63 & -0.27 \\
IYZ & 0.47 & -0.17 \\
\hline
\end{tabular}

If we take a look at the relationship between the dividend and annual RoR at the sectoral level, the results are slightly different from the previous findings of aggregate level as shown in Table 5. Between the annual dividend growth rate and the annual RoR, no robust relationship is present at the sectoral level during the data period. Even though we expect a positive relationship between the two according to the stock valuation model, Table 5 shows mixed relationships with the 6 negative and 5 positive ones out of 11 sectors. However, there is a robust 
negative relationship between the average dividend yield and the annual RoR for all 11 sectors, which is at odds with the DoD theory, even at the sectoral level. The negative relationship is more profound in the following three sectors: energy, industrial, and consumer discretionary. Hence, high dividend yield has a negative impact on the RoR overall, which implies that we should avoid high-dividend-yield sectors in the long-term passive investment using ETFs.

Table 6. Annual rate of return (RoR) between 2010 and 2018 (\%)

\begin{tabular}{ccccc}
\hline ETFs & Top 5 Firms in Dividend Yield & ETF & Top 10 Holding Firms & Difference in RoR between Top 5 and ETF (10 Firms) \\
\hline XLY & 20.14 & 15.89 & 19.28 & $4.25(0.86)$ \\
XLP & 12.94 & 10.15 & 11.21 & $2.79(1.73)$ \\
XLE & 10.66 & 2.41 & 9.80 & $8.25(0.86)$ \\
XLF & 13.92 & 10.30 & 12.67 & $3.62(1.25)$ \\
XLV & 15.36 & 13.89 & 15.49 & $1.47(-0.13)$ \\
XLI & 15.15 & 11.96 & 14.66 & $3.19(0.49)$ \\
XLB & 10.92 & 7.14 & 14.33 & $3.78(-3.41)$ \\
XLK & 15.82 & 14.67 & 16.30 & $1.15(-0.48)$ \\
XLU & 10.20 & 9.98 & 11.14 & $0.22(-0.94)$ \\
IYR & 13.25 & 9.59 & 12.69 & $3.66(0.56)$ \\
IYZ & 7.38 & 5.79 & 7.63 & $1.59(-0.25)$ \\
\hline
\end{tabular}

Note. Using geometric average the annual Rate of Return (RoR) is derived for each sector, and all the dividend payments are included. The expense ratio for first 9 ETFs is $0.13 \%$, whereas it is $0.42 \%$ for both IYR and IYZ.

As the correlation coefficient tests previously show the general relationship between dividend and the annual RoR without performing any annual rebalancing, we extend our research to a specific number of firms in each ETF. Furthermore, we rebalance the portfolio holdings each year based on dividend yield to show more clearly whether the DoD theory is valid at the sectoral level. The results are shown in Table 6. We choose 5 firms (out of 10 firms) whose dividend yields are the highest and stable in each ETF as of the last trading day of each year. The annual RoR of those 5 highest dividend-yield firms is obtained on the last trading day of the following year, and it is compared to that of the ETF and the top 10 holding firms for each sector. The average annual RoRs across 11 sectors for the entire period are shown in Table 6.

Table 6 shows that DoD theory works well in all sectors, as the RoRs of top 5 firms exceed that of ETF. However, the theory is confirmed at the sectoral level only when we assume that no tax and trading costs are present. In other words, if we pay taxes for profits each year along with trading costs, it is hard to find any meaningful difference between the returns of those top 5 firms and that of ETF, except for the energy sector, whose difference is $8.25 \%$. The differences in RoR between the top 5 firms and ETF range between $0.22 \%$ to $8.25 \%$, whereas we have mixed results for the difference between the top 5 firms and the 10 holding firms as shown in the last column of Table 6.

Even though it is hard to identify the exact tax rates on profits, as they depend on the total income of investors, we can assume that the tax portion is not negligible in this research on DoD theory. Hence, the DoD theory does not work well across sectors, with the exception of the energy sector. If both tax and trading costs are reflected, there is no meaningful difference found between the two RoRs. If we compare the RoRs of the top 5 highest dividend-yield firms to the top 10 holding firms, the difference is even weaker, with mixed results. Hence, the DoD theory is not confirmed in our sectoral-level research if we include tax and trading costs. The RoRs of active investors who rebalance their portfolios once a year based on DoD theory are not meaningfully different from those of passive investors who simply use ETFs (or top 10 holding firms) for their long-term investment. Such an occurrence can be possible only in an environment in which there are no taxes and trading costs.

To improve the robustness of our findings, we extended our research to the top 10 highest dividend-yield firms from all 11 sectors. We obtained and compared average annual RoRs of those 10 firms to that of all 11 ETFs. During the same period, the average annual RoRs of 10 firms came to around $13.55 \%$, whereas it was around $10.54 \%$ for all ETFs, as shown in Table 7. Hence, the difference between the two RoRs is around 3\%, which is not be meaningful enough if we include tax and trading costs. 
Table 7. Average rate of return (RoR) for top 10 highest dividend-yield firms and all ETFs (\%)

\begin{tabular}{ccc}
\hline ETFs & Top 10 Firms from Entire Sectors & All ETFs \\
\hline 2010 & 1.06 & -6.27 \\
2011 & 1.51 & 15.38 \\
2012 & 23.26 & 14.13 \\
2013 & 2.98 & -0.88 \\
2014 & 24.36 & 13.39 \\
2015 & 27.24 & 27.58 \\
2016 & 10.31 & 15.27 \\
2017 & 13.93 & 3.28 \\
2018 & 21.15 & 16.93 \\
\hline Average Annual RoR (using Geometric Average) & 13.55 \\
\hline
\end{tabular}

\section{Conclusions}

Even though it is very logical, no robust consensus has been reached regarding the validity of the Dogs of the Dow (DoD) theory at an aggregate equity market level. In this paper, we revisited the theory by extending our research to 11 sectors in the U.S., as few studies have been performed on its validity at the sectoral level. We find that the DoD theory is not confirmed even at the sectoral level, except in one sector (energy), if tax and trading costs are included. This supports the findings by Hirschey (2000) and Kim (2019), among many others. If investors narrow their investments down to the 5 highest dividend-yield firms and rebalance their portfolios once a year on the last trading day, their returns will be higher than the average return of ETF in all 11 sectors. However, this is meaningful only in a world in which there is no tax on profits and trading costs. The finding confirms rather the Efficient Market Hypothesis, and it further proposes that investors shall focus more on sectors that have higher long-term growth prospects rather than trading stocks that have high dividend yields annually. One limitation of our research is that we used the top 5 highest dividend-yield firms out of the 10 largest holding firms that pay stable dividends in each ETF, instead of all holding firms, due mainly to the lack of data availability on the holding history during the period under investigation. Hence, future research can examine all holding firms in order to text the robustness of our findings.

\section{References}

Chong, T. T., \& Kin, K. L. (2010). Does the 'Dogs of the Dow' Strategy Work Better in Blue Chips? Applied Economics Letters, 17(12), 1173-75. https://doi.org/10.1080/17446540902845495

Da Silva, A. L. C. (2001). Empirical Tests of the Dogs of the Dow Strategy in Latin American Stock Markets. International Review of Financial Analysis, 10(2), 187-99. https://doi.org/10.1016/S1057-5219(01)00047-3

Domian, D. L., Louton, D. A., \& Mossman, C. E. (1998). The Rise and Fall of the 'Dogs of the Dow'. Financial Services Review, 7, 145-59. https://doi.org/10.1016/S1057-0810(99)00007-4

Fama, E. F. (1998). Market Efficiency, Long-term Returns and Behavioral Finance. Journal of Financial Economics, 49, 283-306. https://doi.org/10.1016/S0304-405X(98)00026-9

Hirschey, M. (2000). The 'Dogs of the Dow' Myth. The Financial Review, 35(2), 1-15. https://doi.org/10.1111/j.1540-6288.2000.tb01411.x

Kim, D. K. (2019). The Dogs of the Dow Theory - Is It Valid? International Journal of Economics and Finance, 11(5), 43-49. https://doi.org/10.5539/ijef.v11n5p43

Kim, D. K., \& Khanom, N. (2020). The Role of Dividends in Equity Markets: Evidence from Sectoral-Level Analysis. International Journal of Business and Finance Research, 14(1), 23-34. https://ideas.repec.org/a/ibf/ijbfre/v14y2020i1p23-34.html

McQueen, G., Shields, K., \& Thorley, S. (1997). Does the Dow 10 Investment Strategy Beat the Dow Statistically and Economically? Financial Analysts Journal, 53, 66-72. https://dx.doi.org/10.2469/faj.v53.n4.2101

Morningstar. (2018). Report on U.S. Mutual Funds and ETFs. Retrieved from https://newsroom.morningstar.com/newsroom/news-archive/press-release-details/2018/Morningstar-Report s-US-Mutual-Fund-and-ETF-Asset-Flows-for-July-2018/default.aspx

O’Higgins, M., \& Downes, J. (1991). Beating the Dow. New York: Harper Perennial. 
Slatter, J. (1988). Study of Industrial Averages Finds Stocks with High Dividends Are Big Winners. Wall Street Journal (Eastern Edition), August 11.

Soomro, N., \& Haroon, M. A. (2015). Comparison of Dog's of the Dow Strategy. Universal Journal of Management, 3(3), 127-30. https://doi.org/10.13189/ujm.2015.03030

Tissayakorn, K., Song, Y., Qiu, M., \& Akagi, F. (2013). A Study on Effectiveness of the 'Dogs of the Dow' Strategy for the Thai Stock Investment. International Journal of Innovation, Management and Technology, 4(2), 277-80. https://doi.org/10.7763/IJIMT.2013.V4.406

Yan, H., Song, Y., Qiu, M., \& Akagi F. (2015). An Empirical Analysis of the Dogs of the Dow Strategy for the Taiwan Stock Market. Journal of Economics, Business and Management, 3(4), 435-39. https://dx.doi.org/10.7763/JOEBM.2015.V3.224

\section{Copyrights}

Copyright for this article is retained by the author(s), with first publication rights granted to the journal.

This is an open-access article distributed under the terms and conditions of the Creative Commons Attribution license (http://creativecommons.org/licenses/by/4.0/). 